\title{
The role of silver additives in gold-mediated C-H functionalisation
}

\author{
Scott R. Patrick, Ine I. F. Boogaerts, Sylvain Gaillard, Alexandra M. Z. Slawin \\ and Steven P. Nolan*
}

\section{Full Research Paper}

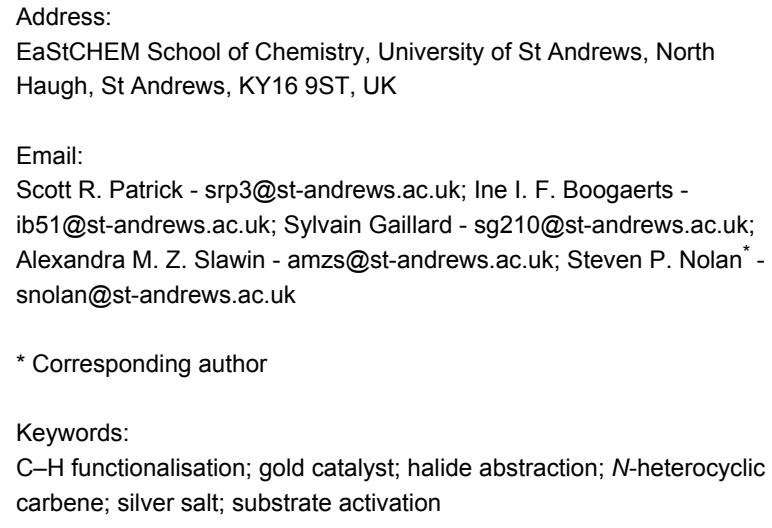

Beilstein J. Org. Chem. 2011, 7, 892-896. doi:10.3762/bjoc.7.102

Received: 18 April 2011

Accepted: 09 June 2011

Published: 01 July 2011

This article is part of the Thematic Series "Gold catalysis for organic synthesis".

Guest Editor: F. D. Toste

(C) 2011 Patrick et al; licensee Beilstein-Institut.

License and terms: see end of document.

\section{Abstract}

The role of silver additives is examined in the context of gold-mediated functionalisation of aromatic $\mathrm{C}-\mathrm{H}$ bonds. Doubt is cast on the commonly cited route of halide abstraction from gold and evidence of substrate activation is given.

\section{Introduction}

The use of gold in homogeneous catalysis is an area where fascinating advances have been realised in the last few years [1-4]. One of these discoveries has focused on the possibility of using gold in metalation reactions [5-8] directly leading to organogold complexes. The further use of organogold complexes bearing $N$-heterocyclic carbenes (NHC) $[9,10]$ as supporting ligands has enabled the isolation of a "golden synthon", [Au(OH)(IPr)] 1 (IPr = 1,3-bis(2,6-diisopropylphenyl)imidazol-2-ylidene), that is able to participate in metalation reactions with aromatic $\mathrm{C}-\mathrm{H}$ bonds (Scheme 1) [11].
The reactivity profile of $\mathbf{1}$ appears linked to bond acidity, and was found to functionalise selectively the most electron-deficient $\mathrm{C}-\mathrm{H}$ bond in a substrate. Unfortunately, the reactivity of $\mathbf{1}$ was limited to bonds with a $\mathrm{p} K_{\mathrm{a}}$ value below 30.4 [12].

Current gold research has shown that silver salts can not only improve reaction times and yields $[13,14]$, but also allow the $\mathrm{C}-\mathrm{H}$ functionalisation of previously unreactive substrates. Larrosa has recently disclosed a mild methodology for the $\mathrm{Au}(\mathrm{I})$-mediated $\mathrm{C}-\mathrm{H}$ functionalisation of 1,3,5-trifluoroben- 


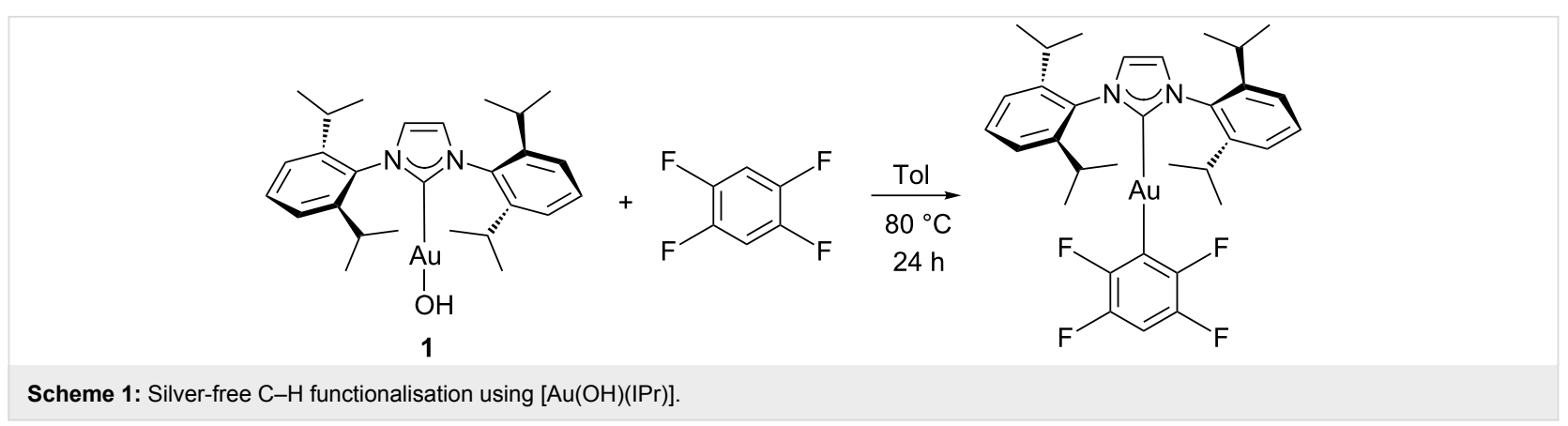

zene (2, p $K_{\text {a DMSO }} 31.5$ [15]) using a mixture of reagents and additives (Scheme 2) [16]. The observation of a high kinetic isotope effect is suggestive of a concerted metalation-deprotonation mechanism, as first suggested for Pd(II) complexes, in which a pivalate ligand behaves as a proton acceptor via a sixmembered transition state [17]. However, addition via a transient $\mathrm{Au}(\mathrm{III})$ hydride would also be consistent with these observations.

\section{Results and Discussion}

We became interested in understanding the mechanistic details of this transformation by identifying the role of the individual components. Reactions were performed between individual reagents and the formation of products was observed by ${ }^{1}$ H NMR spectroscopy. Silver(I) oxide and potassium carbonate both reacted with pivalic acid to form metal pivalates after stirring in toluene at $50{ }^{\circ} \mathrm{C}$ for $20 \mathrm{~h}$. Potassium carbonate did not interact directly with the aryl substrate after stirring in DMF at $50{ }^{\circ} \mathrm{C}$ for $24 \mathrm{~h}$. A stoichiometric reaction between $\mathrm{Ag}_{2} \mathrm{O}$ and the substrate displayed substitution of one of the protons. However, deuterium incorporation experiments were unsuccessful and mass spectrometry on the product was inconclusive.

The reaction depicted in Scheme 2 was performed using a neutral gold(I)-NHC complex. The reaction time was extended to $20 \mathrm{~h}$ in order to obtain optimal results. A reaction involving $[\mathrm{AuCl}(\mathrm{IPr})]$ proceeded with full conversion to product with all additives/reagents present. The removal of potassium carbonate from the reaction had no detrimental effect. Additionally, when it was the only additive used, no reaction took place. These results clearly eliminate the involvement of $\mathrm{K}_{2} \mathrm{CO}_{3}$ in direct deprotonation of the substrate [18]. Potassium carbonate reacts with pivalic acid to form KOPiv, leading to improved yields in the Larrosa methodology. However, this practice was not necessary in our work and the salt did not appear to have any other role in the mechanism. Further reactions did not utilise $\mathrm{K}_{2} \mathrm{CO}_{3}$.

The reaction between [ $\mathrm{AuCl}(\mathrm{IPr})], 2$ and $\mathrm{Ag}_{2} \mathrm{O}$ yielded no product. A stoichiometric addition of pivalic acid was required for the reaction to proceed. The acid was believed to generate the reactive intermediate $3[\mathrm{Au}(\mathrm{OPiv})(\mathrm{IPr})]\left(\mathrm{OPiv}=\left(\mathrm{CH}_{3}\right)_{3} \mathrm{CCO}_{2}\right)$ (Figure 1). To verify this hypothesis, the well-defined complex [19] was used in test reactions following the earlier conditions. Complex 3 reacted with 2 in conjunction with $\mathrm{Ag}_{2} \mathrm{O}$ and gave complete conversion to $4\left[\mathrm{Au}\left(\mathrm{C}_{6} \mathrm{H}_{2} \mathrm{~F}_{3}\right)(\mathrm{IPr})\right]$. This strongly suggests that complex $\mathbf{3}$ is indeed an intermediate. However, the use of a silver salt was essential for the reaction to proceed.

The silver salt was suspected of abstracting the halide from $[\mathrm{AuCl}(\mathrm{IPr})]$ to generate a possibly active cationic gold(I) species [20]. To test this hypothesis, the well-defined cationic complex [( $\left.\left.\mathrm{IPrAu}^{+}\right)(\mathrm{NCMe})\right]\left[\mathrm{BF}_{4}^{-}\right]$[21] was reacted with 2 in the absence of other reagents. No product was observed. Subsequent test reactions were performed using 1 (Table 1, entries 1-3), thus eliminating the possible in situ formation of cationic gold(I). The reaction proved successful in the presence of $\mathrm{Ag}_{2} \mathrm{O}$, suggesting that silver does not generate cationic gold. The reaction with pivalic acid gave a better conversion, indi-

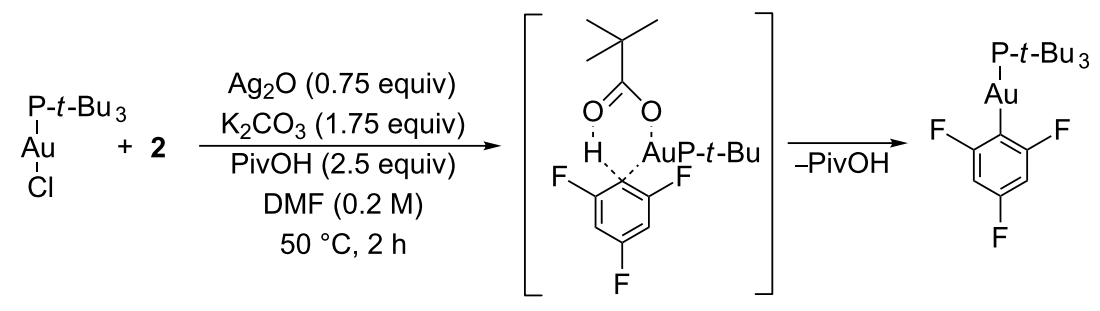




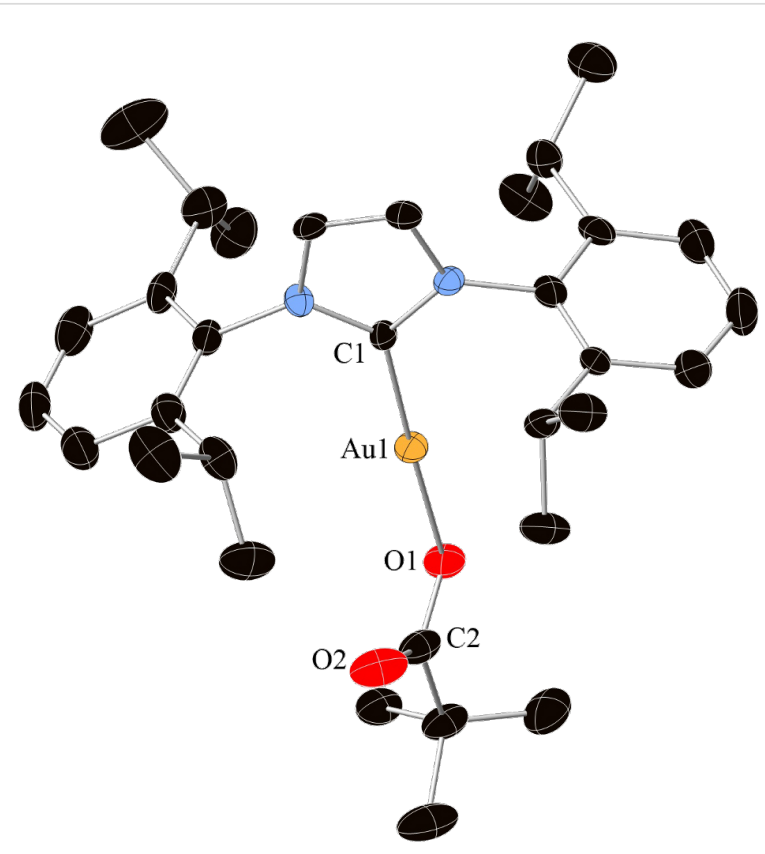

Figure 1: X-ray structure of [Au(OPiv)(IPr)] 3. Thermal ellipsoids are shown at the $50 \%$ probability level. $\mathrm{H}$ atoms are omitted for clarity. Selected bond distances $(\AA)$ and angles $\left({ }^{\circ}\right)$ for 3: Au1-C1 1.978(5), Au1-O1 2.048(4), O1-C2 1.299(8), C2-O2 1.231(9), C1-Au1-O1 178.0(2), Au1-O1-C2 120.7(4), O1-C2-O2 124.6(6). cating that the gold proceeded via complex 3 . Further reactions used $\mathbf{1}$ as the gold species and no longer included PivOH.

The stoichiometric dependence of the silver salt was then examined. Both 0.50 and 0.25 equivalents of $\mathrm{Ag}_{2} \mathrm{O}$ gave poor conversions to the product (entries 4 and 5) and further reducing the loading to 0.1 equivalents stopped the reaction entirely (entry 6).

A range of silver salts was compared in reactions involving 1 and 2. Both $\mathrm{AgF}$ and $\mathrm{AgOAc}$ gave full conversion to product (entries 7 and 8), while the nature of the silver counter ion led reactivity to decrease in the order $\mathrm{Ag}_{2} \mathrm{O}>\mathrm{AgI}>\mathrm{AgO}, \mathrm{AgBF}_{4}$, $\mathrm{AgCl}>\mathrm{Ag}_{2} \mathrm{CO}_{3}, \mathrm{AgOCOCF}_{3}>\mathrm{AgNO}_{3}>\mathrm{AgBr}$. Electronic effects can explain the general reactivity-decreasing trend on going from $\mathrm{AgF}$ to $\mathrm{AgBr}$, but steric factors must also be considered to rationalise the anomalous activity of AgI. The Lewis acidity of the silver salts may contribute to initiate the reaction [22], but unsuccessful reactions using $\mathrm{Al}_{2} \mathrm{O}_{3}, \mathrm{AlCl}_{3}, \mathrm{Cu}_{2} \mathrm{O}$ or $\mathrm{ZnBr}_{2}$ proved otherwise. The existence of a transient anion exchange between the gold ( $\mathrm{AuX}$ ) and the silver salt (AgY) may generate the active "AuY" complex. However, this was disproved by the successful reaction using $\mathrm{AgCl}$. This would implicate $[\mathrm{AuCl}(\mathrm{IPr})]$ as the possible active species. This has

Table 1: C-H functionalisation of 2 using $1 .^{a}$<smiles></smiles>

1<smiles>Fc1cc(F)cc(F)c1</smiles>
AgY $\frac{\text { additive }}{\text { DMF }}$ $50{ }^{\circ} \mathrm{C}$ $20 \mathrm{~h}$

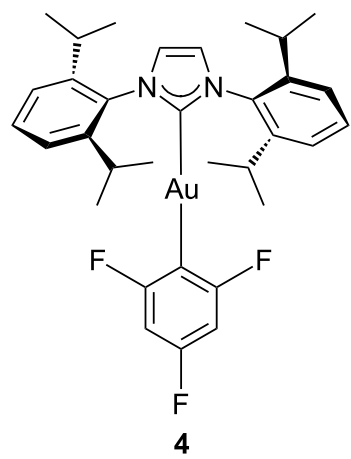

2

\begin{tabular}{llll}
\hline Entry & $\mathrm{AgY}$ & Additive & Conversion ${ }^{\mathrm{b}}(\%)$ \\
1 & $\mathrm{Ag}_{2} \mathrm{O}$ & - & 38 \\
2 & $\mathrm{Ag}_{2} \mathrm{O}$ & $\mathrm{PivOH}$ & 100 \\
3 & - & $\mathrm{PivOH}$ & 0 \\
$4^{\mathrm{c}}$ & $\mathrm{Ag}_{2} \mathrm{O}$ & - & 15 \\
$5^{\mathrm{d}}$ & $\mathrm{Ag}_{2} \mathrm{O}$ & - & 11 \\
$6^{\mathrm{e}}$ & $\mathrm{Ag}_{2} \mathrm{O}$ & - & 0 \\
7 & $\mathrm{AgF}$ & - & 100 \\
8 & $\mathrm{AgOAc}$ & - & 100 \\
\hline
\end{tabular}

aUnless otherwise noted, all reactions were carried out with 1 ( 1 equiv), 2 (4.5 equiv), salt (1.5 equiv) and additive ( 2.5 equiv) in a $0.2 \mathrm{M}$ DMF solution. ${ }^{b}$ Conversion to product was determined by ${ }^{1} \mathrm{H}$ NMR analysis relative to $1 .{ }^{\mathrm{c}} \mathrm{AgY}$ ( 0.5 equiv) was used. ${ }^{\mathrm{d}} \mathrm{AgY}\left(0.25\right.$ equiv) was used. ${ }^{\mathrm{e}} \mathrm{AgY}(0.1 \mathrm{equiv})$ was used. 
already been discounted since it was shown to be unreactive in the model $\mathrm{C}-\mathrm{H}$ bond functionalisation reaction.

To complete the examination of possibly important parameters enabling the reaction, the role of solvents was investigated. Solvent screening showed that the reaction could proceed in THF (59\% conversion), DMF (38\%), toluene (35\%), 1,4dioxane $(21 \%)$ and poorly in cyclopentyl methyl ether (CPME) (3\%). The conversions do not mirror the polarity of the solvents and the silver salts were sparingly soluble in every solvent tested [23].

As the functionalisation of $\mathrm{C}-\mathrm{H}$ bonds was now found possible in the presence of silver additives, we reasoned that a test of the observation was to carry out a carboxylation reaction [12] with substrate $\mathbf{2}$ using catalyst $\mathbf{1}$ under optimised carboxylation conditions (Scheme 3).

$$
\begin{gathered}
\mathrm{THF}, 60^{\circ} \mathrm{C} \\
16 \mathrm{~h}
\end{gathered}
$$

Scheme 3: Carboxylation of 2 using 1 and $\mathrm{Ag}_{2} \mathrm{O}$

The general procedure employed 2, 1 (3 mol \%), $\mathrm{Ag}_{2} \mathrm{O}$ ( $3 \mathrm{~mol} \%$ ) and three equivalents of potassium hydroxide. Gratifyingly, whereas a reaction in the absence of silver leads to no carboxylation product, the addition of silver leads to formation of 2,4,6-trifluorobenzoic acid (5). The use of a stoichiometric amount of $\mathrm{Ag}_{2} \mathrm{O}$ results in aggregation of the reagents that seemingly affects mass transport of $\mathrm{CO}_{2}$ and halts the reaction. However, the catalytic use of $\mathrm{Ag}_{2} \mathrm{O}$ gave a $22 \%$ isolated yield of 5 . This observation clearly shows that silver can have a positive role in the carboxylation of $\mathrm{C}-\mathrm{H}$ bonds.

\section{Conclusion}

The $\mathrm{C}-\mathrm{H}$ functionalisation of arenes using (NHC)gold(I) complexes has been shown to be significantly affected by the leaving group on the gold. The gold(I) chloride may only react by first forming the intermediates $\mathbf{1}$ or $\mathbf{3}$. The gold(I) pivalate gives full conversion and is believed to form a six-membered transition state with the substrate. The gold(I) hydroxide gives incomplete conversion to product and the reaction pathway is currently unknown. The use of $\mathrm{K}_{2} \mathrm{CO}_{3}$ was shown to be unnecessary. The solvent used affects the conversion, although polarity appears not to be a factor. Silver does not act as a simple Lewis acid, as shown by the failure of other metal salts to facilitate the reaction. The reaction was shown to require stoichiometric amounts of the silver salt. The failed reaction of a cationic gold species hints that the silver salt has a role other than abstracting halides. The successful reactions of $\mathbf{1}$ and $\mathbf{3}$, which cannot be dissociated by silver salts, reinforce this idea. The choice of silver salt is very important, and has been shown to widely influence the conversion achieved. The high electronegativity of the silver counter ion is of great importance. Finally, evidence of an interaction between silver salts and the substrate suggests that silver activates the aryl $\mathrm{C}-\mathrm{H}$ bond and is then implicated in a transmetalation reaction with gold to provide the product. The value of silver additives in catalytic carboxylation of $\mathrm{C}-\mathrm{H}$ bonds was then illustrated in the formation of 2,4,6-trifluorobenzoic acid, which was hitherto unattainable by gold(I)-catalysed carboxylation using catalyst $\mathbf{1}$ alone. This may provide a method to increase the range of $\mathrm{C}-\mathrm{H}$ bonds amenable to functionalisation through gold-mediated carboxylation. Studies aimed at examining the extent of this effect are ongoing in our laboratories.

\section{Supporting Information}

\section{Supporting Information File 1}

Detailed experimental procedures for the synthesis of complexes 3-5.

[http://www.beilstein-journals.org/bjoc/content/ supplementary/1860-5397-7-102-S1.pdf]

\section{Acknowledgements}

We are grateful to EPSRC and ERC (Advanced Researcher Award (FUNCAT) to SPN) for funding. SPN is a Royal Society-Wolfson Research Merit Award holder.

\section{References}

1. Hashmi, A. S. K. Chem. Rev. 2007, 107, 3180-3211. doi:10.1021/cr000436x

2. Gorin, D. J.; Sherry, B. D.; Toste, F. D. Chem. Rev. 2008, 108, 3351-3378. doi:10.1021/cr068430g

3. Jiménez-Núñez, E.; Echavarren, A. M. Chem. Rev. 2008, 108, 3326-3350. doi:10.1021/cr0684319

4. Marion, N.; Nolan, S. P. Chem. Soc. Rev. 2008, 37, 1776-1782. doi:10.1039/b711132k

5. Partyka, D. V.; Zeller, M.; Hunter, A. D.; Gray, T. G. Angew. Chem., Int. Ed. 2006, 45, 8188-8191. doi:10.1002/anie.200603350

6. Partyka, D. V.; Updegraff, J. B., III; Zeller, M.; Hunter, A. D.; Gray, T. G. Organometallics 2009, 28, 1666-1674. doi:10.1021/om800746u

7. Gao, L.; Peay, M. A.; Partyka, D. V.; Updegraff, J. B., III; Teets, T. S.; Esswein, A. J.; Zeller, M.; Hunter, A. D.; Gray, T. G. Organometallics 2009, 28, 5669-5681. doi:10.1021/om9005214

8. Partyka, D. V.; Esswein, A. J.; Zeller, M.; Hunter, A. D.; Gray, T. G. Organometallics 2007, 26, 3279-3282. doi:10.1021/om700346v 
9. Díez-González, S.; Marion, N.; Nolan, S. P. Chem. Rev. 2009, 109, 3612-3676. doi:10.1021/cr900074m

10. Nolan, S. P. Acc. Chem. Res. 2011, 44, 91-100. doi:10.1021/ar1000764

11. Gaillard, S.; Slawin, A. M. Z.; Nolan, S. P. Chem. Commun. 2010, 46, 2742-2744. doi:10.1039/c0cc00018c

12. Boogaerts, I. I. F.; Nolan, S. P. J. Am. Chem. Soc. 2010, 132, 8858-8859. doi:10.1021/ja103429q

13. Zhang, Z.; Bender, C. F.; Widenhoefer, R. A. Org. Lett. 2007, 9 , 2887-2889. doi:10.1021/ol071108n

14. Marion, N.; Ramón, R. S.; Nolan, S. P. J. Am. Chem. Soc. 2009, 131, 448-449. doi:10.1021/ja809403e

15. Shen, K.; Fu, Y.; Li, J.-N.; Liu, L.; Guo, Q.-X. Tetrahedron 2007, 63, 1568-1576. doi:10.1016/j.tet.2006.12.032

16. Lu, P.; Boorman, T. C.; Slawin, A. M. Z.; Larrosa, I. J. Am. Chem. Soc. 2010, 132, 5580-5581. doi:10.1021/ja101525w

17. Lafrance, M.; Fagnou, K. J. Am. Chem. Soc. 2006, 128, 16496-16497. doi:10.1021/ja067144j

18. Vechorkin, O.; Hirt, N.; Hu, X. Org. Lett. 2010, 12, 3567-3569. doi:10.1021/ol101450u

19. The CIF file for $\mathbf{3}$ has been deposited with the CCDC, No. 815857. Copies of the data can be obtained free of charge on applications to CCDC, 12 Union Road, Cambridge, CB2 1EZ, UK; fax: +44 1223336 033; http://www.ccdc.cam.ac.uk; e-mail: deposit@ccdc.cam.ac.uk.

20. Pan, K.; Noël, S.; Pinel, C.; Djakovitch, L. J. Organomet. Chem. 2008, 693, 2863-2868. doi:10.1016/j.jorganchem.2008.05.042

21. de Frémont, P.; Stevens, E. D.; Fructos, M. R.; Díaz-Requejo, M. M.; Pérez, P. J.; Nolan, S. P. Chem. Commun. 2006, 19, 2045-2047. doi:10.1039/B601547F

22. Kanyiva, K. S.; Löbermann, F.; Nakao, Y.; Hiyama, T. Tetrahedron Lett. 2009, 50, 3463-3466. doi:10.1016/j.tetlet.2009.02.195

23. The heterogeneous activity of the silver was examined by introducing mercury to the reaction conditions set out in Table 1, entry 1. Elemental mercury blocks the pores of solids with large surface areas, thus disabling heterogeneous reactivity (see [24]). Product $\mathbf{4}$ was successfully generated, strongly suggesting that only the homogeneous silver is involved in the reaction.

24. Whitesides, G. M.; Hackett, M.; Brainard, R. L.; Lavalleye, J.-P. P. M.; Sowinski, A. F.; Izumi, A. N.; Moore, S. S.; Brown, D. W.; Staudt, E. M. Organometallics 1985, 4, 1819-1830. doi:10.1021/om00129a023

\section{License and Terms}

This is an Open Access article under the terms of the Creative Commons Attribution License

(http://creativecommons.org/licenses/by/2.0), which permits unrestricted use, distribution, and reproduction in any medium, provided the original work is properly cited.

The license is subject to the Beilstein Journal of Organic Chemistry terms and conditions:

(http://www.beilstein-journals.org/bjoc)

The definitive version of this article is the electronic one which can be found at:

doi:10.3762/bjoc. 7.102 